\title{
Sense of Coherence, Spirituality, Stress and Quality of Life in Chronic Illness
}

Cheryl Delgado

Cleveland State University, c.delgado@csuohio.edu

Follow this and additional works at: https://engagedscholarship.csuohio.edu/nurs_facpub

Part of the Nursing Commons

How does access to this work benefit you? Let us know!

\section{Publisher's Statement}

This is the accepted version of the following article: Delgado, C. (2007). Sense of coherence, spirituality, stress and quality of life in chronic illness. Journal of Nursing Scholarship, 39(3), 229-234. doi:10.1111/j.1547-5069.2007.00173.x , which has been published in final form at http://onlinelibrary.wiley.com/doi/10.1111/j.1547-5069.2007.00173.x/abstract

\section{Recommended Citation}

Delgado, Cheryl, "Sense of Coherence, Spirituality, Stress and Quality of Life in Chronic Illness" (2007). Nursing Faculty Publications. 13.

https://engagedscholarship.csuohio.edu/nurs_facpub/13

This Article is brought to you for free and open access by the School of Nursing at EngagedScholarship@CSU. It has been accepted for inclusion in Nursing Faculty Publications by an authorized administrator of EngagedScholarship@CSU. For more information, please contact library.es@csuohio.edu. 


\title{
Sense of Coherence, Spirituality, Stress and Quality of Life in Chronic IIIness
}

\author{
Cheryl Delgado
}

\begin{abstract}
Purpose: To investigate the relationship between sense of coherence and spirituality and their association with perceptions of stress, and quality of life.

Methods: Questionnaires mailed to nonhospitalized patients with chronic obstructive pulmonary disease. Data analyses included descriptive statistics, Pearson's correlations, multiple regressions, and ANOVA.

Results: High sense of coherence (SOC) and spirituality were correlated with low stress and high quality of life (QoL). Neither SOC nor spirituality related significantly to objective symptom severity. In regression analyses $73.2 \%$ of the variance in QoL was explained by $S O C$, the $F E V_{1} / F V C$ ratio, and functional ability.

Conclusions: Psychosocial factors are important in patients' cognitive interpretations of illness. SOC and spirituality may buffer stress in the context of chronic illness.
\end{abstract}

[Key words: sense of coherence, spirituality, stress, quality of life, chronic illness, chronic obstructive pulmonary disease]

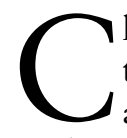

hronic illnesses impose heavy physical, social, emotional, and economic burdens on patients, families, and society (Bishop, 2005). Each patient's response to this stress is unique, and people with the same medical diagnosis and comparable disease progression might rate their quality of life differently. McMahon (2002) noted that ratings of life quality within the context of a chronic illness depended on subjective responses to the changes produced by the disease. A growing body of research exists on chronic disease and quality of life (Cuijpers, van Lammern, \& Duzijn, 1999; Headly, 2004; Liveneh, 2004; Luk, 2004; Weinert, 2005), but little research has been done on how sense of coherence, spirituality, or other psychosocial factors might be related to stress and quality of life.

One explanation for the variations in stress response was proposed in Antonovsky's salutogenic theory of health (1979). This theory indicate that a person's sense of coherence predicts the ability to recognize and utilize resources. Sense of coherence is a worldview that enables people to use resources effectively. Antonovsky identified several categories of resources, including spirituality, recently a focus of research in healthcare (Holt, 2006; Meraviglia, 2006; Schultz, 2005; Tanyi, 2006).

The purpose of the current study was to explore the relationship between two intrinsic characteristics of the person: sense of coherence and spirituality, and to identify their effects on individual perceptions of stress and quality of life.
Chronic obstructive pulmonary disease was used as an exemplar for conditions that cause chronic stress.

Affecting all races and ethnicities, chronic obstructive pulmonary disease (COPD) is an exemplar for chronic illness. It requires more than 30 billion dollars in American healthcare costs annually (American Lung Association, 2002). A study of women with COPD showed greater impairment of activities of daily life, increased social isolation, and more anxiety and depression than in women with heart disease (Reidinger, Dracup, \& Brecht, 2002). No reported prior study has been focused on both sense of coherence and spirituality in people suffering from chronic obstructive pulmonary disease.

\section{Methods}

\section{Operational Definitions and Instrumentation}

Sense of coherence is defined as "a global orientation that expresses the extent to which one has a pervasive, 
enduring though dynamic feeling of confidence" that the world is meaningful, understandable, and manageable (Antonovsky, 1979, p.123). Sense of coherence (SOC) is measured with the short form Orientation to Life questionnaire developed by Antonovsky in 1987. Spirituality is a quality of the person derived from the social and cultural environment that involves faith, a search for meaning, a sense of connection with others, and a transcendence of self, resulting in a sense of inner peace and well being (Delgado, 2005). Spirituality was measured with the Spiritual Transcendence Scale (STS) which indicates that spirituality is an aspect of personality (Piedmont, 2002).

Stress was defined for this study as a person's interpretation of an event as stressful, or a demand that exceeds the person's immediate resources for response. It was measured with the Perceived Stress Scale (PSS) developed by Cohen, Kamarck, and Mermelstein, with well-established validity and reliability (Cohen et al., 1983). Quality of life lacks a universally accepted definition, but for the purpose of this study was defined as a person's satisfaction with certain areas of life. The Quality of Life Index - Pulmonary Version III (QLI-PV) by Ferrans and Powers (1992) was used to measure quality of life. It consists of a self-rating on 36 items in five broad areas (health, function, social and economic, psychological and spiritual, and family), and is weighted for personal importance.

Demographic data were collected on gender, race, income, education, marital status and household composition, chronic illnesses, disabilities, medication, and the need for caregiver assistance. Subjective symptom severity was measured with a modified Borg scale on which the participant self-rates on scales of 0 to 10 the feeling of shortness of breath and ability to function. Objective data on symptom severity were collected as pulmonary function test results and use of home oxygen. Characteristics of the instruments used in the study are shown in Table 1.

\section{Design and Sample}

Before implementation of the study, all necessary permissions were obtained from the institutional review boards of participating institutions. Informed consents were obtained from all participants.

The study design was a cross-sectional mailed survey to people with COPD. Consistent with HIPPA regulations a two-step recruitment process was used, in which 1,154

\begin{tabular}{|c|c|c|c|c|}
\hline & SOC 13 & STS & PSS & QLI \\
\hline Mean $(S D)$ & $67.9(15.1)$ & $87.5(11.3)$ & $22.8(8.4)$ & $19.6(5.6)$ \\
\hline Actual range of scores & $21-90$ & $55-112$ & $3-51$ & $5.6-29.2$ \\
\hline Number of items & 13 & 24 & 14 & 72 \\
\hline Possible range of scores & $13-91$ & $15-120$ & $0-56$ & $0-30$ \\
\hline Cronbach alpha & .75 & .72 & .75 & .94 \\
\hline
\end{tabular}

COPD patients seen in the pulmonary services of a large tertiary referral center were informed of the study by their physicians. Two hundred eighty people interested in participation returned postcards providing their addresses, a return rate of $26 \%$. Each of the 280 people was sent a packet containing a study description, informed consents, questionnaires, and self-addressed stamped envelopes to return the completed materials. The return rate for completed packets was $64 \%$ of the 280 mailed, for a final sample of 181 for the study. Because some pulmonary function data retrieved from the medical records with permission of the participants were incomplete, some data analyses were calculated with a smaller number. No participant was an impatient in an acute care facility or nursing home at the time of the survey.

\section{Statistical Analysis}

Statistical calculations done with the Statistical Package for the Social Sciences (SPSS) included descriptive and frequency statistics, determination of Pearson $r$ correlation coefficients (reported as a $p$ value), multiple regressions, and ANOVA. Spearman Rho values were obtained to confirm the accuracy of the Pearson correlations on the major variable correlations and were identical to the Pearson $r$ values obtained. In the following report only Pearson $r$ coefficients are reported.

Calculation of statistics for the QLI-PV were done with a scoring syntax provided by Ferrans and Powers (2006). This syntax allowed for missing data through an imbedded calculation in the syntax to substitute a neutral value for missing items. Because all the questionnaires used had a neutral midpoint value on the scales anchored at either extreme by a positive or negative value, this solution of a neutral substitution was also applied to missing data in the SOC, PSS, and STS questionnaires so as not to skew the total score. Most questionnaires were returned complete; overall less than $5 \%$ of all items were missing from questionnaires and demographic information forms.

\section{Findings}

\section{Sample}

The total sample was 181 . Slightly more than half of the participants were male $(53.6 \%)$. The age of the participants ranged from 30 years to 87 years with the largest number between 60 and 79 years of age $(61.8 \%)$. Some participants $(7.8 \%)$ were younger than 50 , half were 66 years of age or older, and nearly $10 \%$ were 80 or above. The majority of participants identified themselves as non-Hispanic Caucasians $(90.6 \%)$. Slightly more than $8 \%$ were African American and one participant identified himself as Native American. The demographic characteristics of the sample approximate national data of people with COPD (U.S. Department of Health and Human Services, 2007).

Most participants in this study were married and living with their spouse $(66.3 \%)$ Almost one quarter $(22.1 \%)$ lived alone, $12.2 \%$ lived with adult children or 
grandchildren, and $1.7 \%$ lived with a nonrelative. Most participants identified themselves as Christian (93.7\%), a small percentage $(4 \%)$ identified themselves as Jewish, and less than $2 \%$ listed themselves as atheist, agnostic, or left this question unanswered.

Participants were well educated. Many had attended some college $(27.1 \%)$ or were college graduates $(12.7 \%)$ and $11 \%$ had completed graduate school or professional programs; $17.2 \%$ were still working full or part time, and half were retired. One quarter were receiving disability payments for COPD. Incomes ranged from less than USD 10,000 a year to more than USD 200,000 yearly; most were between 10,000 and 50,000 USD a year.

Participants had COPD for periods ranging from 9 to 33 years, with a mean of 7.8 years. Slightly more than half $(51.9 \%)$ of the participants had been hospitalized for COPD at some time; $18.2 \%$ said they had been hospitalized in the past 12 months for COPD; and $28.7 \%$ had been hospitalized in the past year for other health problems. Some participants had multiple medical co-morbidities such as other pulmonary problems and cardiovascular, rheumatic, and endocrine diseases. Four had undergone lung or heart-lung transplant. Just over $8 \%$ of all participants in the study said they had been treated in the past for lung cancer; none were currently receiving chemotherapy or other treatment for their cancers.

\section{Subjective Measures of Symptom Severity}

Most participants believed that they were able to care for themselves without assistance $(71.8 \%)$, and few $(3.3 \%)$ considered themselves to be very dependent on others. Participants were asked to rate their shortness of breath (SOB) over the past 24 hours on a modified Borg scale, 0 (no difficulty), to 10 (most severe difficulty). Most (66.3\%) responded that they were not or only moderately short of breath, some $(13.2 \%)$ rated their breathing as very severely impaired, but no participant rated shortness of breath as maximally severe.

Ability to function was rated by participants on a similar scale. Three-fourths responded that they had no or only moderately impaired ability to function, and only $5.6 \%$ rated their ability to function as very severely impaired. No participant rated functional ability as maximally difficult or unable to function. Both SOB and ability to function scales showed a slight skew to the lower values.

\section{Objective Measures of Symptom Severity}

In this study, $53 \%$ of all participants said they used oxygen; $39.7 \%$ said they used oxygen all the time. Because disease severity in COPD is more accurately measured with pulmonary function testing, this study included data on pulmonary mechanics from spirometric determination of forced vital capacity (FVC), forced vital capacity in one second $\left(\mathrm{FEV}_{1}\right)$ and the ratio, $\mathrm{FEV}_{1} / \mathrm{FVC}$. Every effort was made to use results that were the most recent or were done closest to the time the participant completed the questionnaires; test results more than 1 year old were not used. Gas exchange parameters were not included in the study because this information was not consistently recorded and because some patients were using oxygen, making comparisons between patients difficult. Participants had a wide range of values for airflow reduction, from normal to severely reduced.

The $\mathrm{FEV}_{1} / \mathrm{FVC}$ ratio is a predictor of respiratory disease mortality (American Thoracic Society, 2002; Global Initiative for Chronic Obstructive Lung Disease, 2005). In this study, the $\mathrm{FEV}_{1} / \mathrm{FVC}$ was recorded as decimal (real number) rather than a percentage because it is a ratio that already corrects for other factors influencing FVC and FEV . All participants with COPD were included regardless of disease severity or reversibility of airway obstruction with the idea that a range of lung function parameters would enhance distinguishing the effects of the physiologic abnormalities from the effects of the psychological and spiritual parameters.

\section{Correlations Among Major Variables}

This study showed that participants with the strongest sense of coherence were also more spiritual, perceived less stress, and rated their quality of life as better. Strong sense of coherence was associated with less difficulty breathing and better ability to function, but sense of coherence was not significantly related to pulmonary function scores. No association was found between spirituality and breathlessness, functional impairment, or pulmonary function scores.

Participants who felt more stressed reported more shortness of breath and functional impairment. Stress scores were not related to pulmonary function measures. Participants who rated themselves as sickest also rated quality of life as lower. The sole co-morbid condition associated with functional impairment and decreased quality of life was renal disease. A summary of the correlations among the psychosocial variables of the study, quality of life, and subjective (self-reported) and objective (measured) symptom severity is presented in Table 2 .

\section{Relative Contributions of Psychosocial Factors and Symptom Severity}

Linear multiple regressions were calculated to determine the contribution of the demographic variables to the QLI-PV scores representing quality of life. The demographic variables gender, age, race, marital status, education, income, employment status, religion, and living alone were regressed against quality of life. A single model was identified, accounting for $18.6 \%$ of the variance in scores. Of the demographic variables, annual income and age were the significant contributors $(p>.01)$. The amount of variance explained by demographic variables was not large. A more diverse sample could produce a different result.

A linear multiple regression calculation was also done for the major psychosocial variables of the study (sense of coherence, spirituality, and perceived stress), with quality of life as the constant. Two models were identified. In the 
Table 2. Correlations of the Major Variables in the Study

\begin{tabular}{|c|c|c|c|c|c|c|c|c|c|}
\hline & $\begin{array}{c}\text { Sense of } \\
\text { coherence }\end{array}$ & Spirituality & Stress & $\begin{array}{c}\text { Quality } \\
\text { of life }\end{array}$ & $\begin{array}{c}\text { Shortness } \\
\text { of breath }\end{array}$ & $\begin{array}{l}\text { Ability } \\
\text { to function }\end{array}$ & $\mathrm{FEV}_{1}$ & FVC & Ratio \\
\hline Sense of coherence & 1.000 & & & & & & & & \\
\hline Spirituality & $.271^{* *}$ & 1.000 & & & & & & & \\
\hline Stress & $-.687^{* *}$ & $-.308^{* *}$ & 1.000 & & & & & & \\
\hline Quality of life & $.691^{* *}$ & $.295^{* *}$ & $-.674 * *$ & 1.000 & & & & & \\
\hline Shortness of breath & $-.356^{* *}$ & -.122 & $.374 * *$ & $-.552^{* *}$ & 1.000 & & & & \\
\hline Ability to function & $-.302^{* *}$ & -.038 & $.371^{* *}$ & $-.496 * *$ & $.685^{* *}$ & 1.000 & & & \\
\hline $\mathrm{FEV}_{1}$ & .050 & -.013 & .088 & .137 & $-.226 *$ & $-.233^{* *}$ & 1.000 & & \\
\hline FVC & .059 & .136 & -.001 & .082 & -.139 & -.156 & $.575^{* *}$ & 1.000 & \\
\hline $\mathrm{FEV}_{1} / \mathrm{FVC}$ ratio & .033 & -.100 & -.118 & .135 & $-.255^{* *}$ & $-.232 *$ & $.766 * *$ & -.041 & 1.000 \\
\hline
\end{tabular}

first, sense of coherence was found to explain nearly half the variance, and in the second the negative effect of perceived stress added slightly to the variance.

When variables representing symptom severity (shortness of breath, impaired ability to function, $\mathrm{FEV}_{1}$ percentage, FVC percentage, $\mathrm{FEV}_{1} / \mathrm{FVC}$ ratio, oxygen saturation on room air, and need for caregivers) were regressed in stepwise method to determine the contributions of each to quality of life, a single model accounting for nearly half of the variance $(48.4 \%)$ was found, with impaired ability to function scores as significant. Because variables entered first may "steal" variance from subsequently entered variables, this regression was done twice, reversing the order of the variables entered, with no difference in the results.

A linear multiple regression was conducted to determine the relative contribution of all the psychosocial variables and all of the symptom severity measures, producing three models. Sense of coherence was the most influential predictor, but PFT ratio and impaired ability to function scores were also significant. Functional impairment had a negative influence. The order in which the variables were entered did not change the finding. A very high percentage of the variance $(73.2 \%)$ in quality of life was accounted for by sense of coherence, the objective $\mathrm{FEV}_{1} / \mathrm{FVC}$ ratio, and the perception of impaired ability to function.

To further explore the effect of symptom severity, the $\mathrm{FEV}_{1} / \mathrm{FVC}$ ratio scores of participants were recoded into quartiles based on disease severity for an ANOVA analysis. No significant differences were found between the groups using the questionnaire scores for sense of coherence, spirituality, perceived stress, and quality of life. Demographic data for the severity groupings based on $\mathrm{FEV}_{1} / \mathrm{FVC}$ scores also showed no group differences.

Because COPD is a progressive disease, correlations were examined between the sense of coherence, spirituality, stress, and quality of life scores with participant age and length of time with COPD. Age and length of time with COPD were significantly related, and older participants had higher sense of coherence scores, lower stress scores, and higher quality of life scores.

\section{Discussion}

Sense of coherence was an important contributor to participants' perceptions of quality of life. The finding that sense of coherence and spirituality both had negative relationships with stress is compatible with Antonovsky's health model in which successful coping or adaptation is equivalent to "eustress." The negative correlation of stress and quality of life is well established.

All measures of symptom severity, subjective and objective, have the potential to affect both a person's perceptions of stress and quality of life, as does the presence and use of resources. Sense of coherence correlated with the subjective ratings of symptom severity, but was not related to objective measures, with the exception of the need for caregiver assistance. People with COPD in this study with high sense of coherence reported less shortness of breath and functional impairment, regardless of the objective measures of symptom severity.

An interesting finding was the large proportion of variance explained by sense of coherence in the regression models. That finding showed that perceptions of stress were influenced by factors not measured by objective disease parameters, indicating the importance of a person's cognitive interpretation of illness. Participants with a strong sense of coherence perceived their life quality as better, regardless of their objective symptom severity. The findings in relation to spirituality and stress and quality of life were similar to that of sense of coherence, but were more subtle.

Sense of coherence was not related to the physical measures of symptom severity from the pulmonary function tests, but was related to the subjective ratings of breathlessness and impaired function and the need for caregivers. People with lower sense of coherence scores more often had caregiver assistance. One interpretation could be that these participants were sicker, but another possibility is that participants with lower sense of coherence were less able to cope without assistance.

The findings of this study reinforce a finding of Motzer and Stewart (1987) that high sense of coherence is related 
to high rating of quality of life. Using the participants' selfrated quality of life instead of ratings from another person was based on the assumption that quality of life is a perceptual evaluation. Ferrans and Powers' use of satisfaction as the standard for determining global quality of life is relevant to interpreting these results. Had quality of life been defined as happiness or by using arbitrary objective measures, quality of life ratings may not have been the same. Because participants in this study were also older and better educated than the general population, their ratings of quality of life might be different from the general population.

The study sample included many people eligible for Medicare and for whom healthcare insurance and costs were not a primary concern. The regression of demographic variables against quality of life indicated that material resources can relieve some of the financial stress of chronic illness. Most participants needed transportation, oxygen equipment, and medications. Having adequate monetary resources was more important than was gender, education, or religion.

In this study, no participant, regardless of symptom severity, sense of coherence, or spirituality rated their shortness of breath or ability to function as maximally impaired. This finding could reflect the normalization described by Miller (2000) in chronic disease. One way in which people adapt to altered, often impaired, conditions is by resetting their expectations to make the current level of difficulty the norm. Alternately, the low return rate opens the possibility that the achieved sample represents the most functional among those with COPD recruited for the study, but the objective measures for severity indicate that many in the study had severe disease. In fact, two participants died within 3 weeks of completing the survey.

\section{Limitations of the Study}

A major limitation of the study was the low return rate and possible self-selection of the sample. The complicated two-step recruitment may account for the initial low response rate. Because the number of non-Caucasian participants was low, replication of the study in a more racially diverse population would be desirable.

The generalizability of the findings is limited by the conceptual definitions of spirituality and quality of life. Spirituality in this study was viewed as a personality factor and not necessarily theistic. Not all researchers would use such a broad interpretation. Quality of life was defined as satisfaction with various aspects of life as defined and weighted by the participants. This interpretation is subject to normalization by the participant. As a counterpoint, demographic variables such as education and income were regressed against the quality of life scores so as to not overlook any marked disparities between the participants' view of quality of life and more general objective measures.

Pulmonary function data were not obtained on every participant, and the pulmonary data were a mix of spirometry and full PFT results. For this reason, not all parameters were used, only those most consistently reported. Better results could be obtained if pulmonary function tests were performed at the time of the survey.

\section{Conclusions}

The findings of this study indicate that strong sense of coherence and strong spirituality were associated with higher ratings of quality of life, but that these factors were not the only or necessarily the most significant factors in rating quality of life. While sense of coherence and spirituality appear to be important, they cannot be assumed to decrease stress or increase quality of life. Although these positive correlations do not indicate causal relationships, this information enhances understanding the dynamics of stress and response in chronically ill patients with respiratory disease, and it should be useful in further nursing research in this area.

This study may be useful in identifying directions for additional research. Further study might indicate a threshold at which the positive effects of sense of coherence and spirituality decline with increasing physical deterioration. Length of time with a chronic illness might also be important, as well as a possible cumulative effect with concurrent chronic illnesses. These and other questions are areas for further inquiry.

\section{References}

American Lung Association. (2002 March). Trends in chronic bronchitis and emphysema: Morbidity and mortality. Retrieved November, 8, 2002, from www.lungusa.org/data/copd/COPD/.pdf

Antonovsky, A. (1979). Health, stress and coping. San Francisco: JosseyBass.

Bishop, M. (2005). Quality of life and psychosocial adaptation to chronic illness and disability. Rehabilitation Counseling Bulletin, 48(4), 219231.

Cohen, S., Kamarck, T., \& Mermelstein, R. (1983). A global measure of perceived stress. Journal of Health and Social Behavior, 24, 385-396.

Cuijpers, P., van Lammern, P., \& Duzijn, B. (1999). Quality of life: Relation between quality of life and chronic illness in elderly living in residential homes: a prospective study. International Psychogeriatrics, 11, 445-54.

Delgado, C. (2005). A discussion of the concept of spirituality. Nursing Science Quarterly, 118(2), 157-162.

Ferrans, C., \& Powers, M. (2006). Quality of life index. Retrieved January, 25, 2006, from www.uic.edu/orgs/qli

Ferrans, C., \& Powers, M. (1992). Psychometric assessment of the Quality of Life Index. Advances in Nursing and Health, 15, 29-38.

Global Initiative for Chronic Obstuctive Lung Disease. (2005). Executive summary: Global strategy for the diagnosis, management and prevention of chronic obstructive lung disease. Retrieved February 5, 2005, from http://www.copd-international.com/Library/stages/htm

Headly, J.A. (2004). The effects of selected exercise on fatigue and quality of life in women with advanced breast cancer. Oncology Nursing Forum, 31(5), 977-983.

Holt, C.L. (2006). Perceptions of religion: Health communication among African American church members. Qualitative Health Research, 16(2), 268-281.

Liveneh, H. (2004). Patterns of psychological adaptation to chronic illness and disability: A cluster approach. Psychology, Health and Medicine, 54(2), 85-96.

Luk, W.S. (2004). The HRQoL of renal transplant patients. Journal of Clinical Nursing, 13(2), 201-209. 
McMahon, A.M. (2002). Coping with chronic lung disease: Maintaining quality of life. In J.F. Miller (Ed.), Coping with chronic illness: Overcoming powerlessness (3rd ed.; pp. 327-376). Philadelphia: F.A. Davis.

Meraviglia, M. (2006). Effects of spirituality on breast cancer survivors. Oncology Nursing Forum, 33(1), E1-7.

Miller, J.F. (2000). Analysis of coping with illness. In J.F. Miller (Ed.), Coping with chronic illness: Overcoming powerlessness (3rd ed.; pp. 21-54). Philadelphia: F.A. Davis.

Motzer, S.U., \& Stewart, B.J. (1996). Sense of coherence as a predictor of quality of life in persons with coronary artery disease surviving cardiac arrest. Research in Nursing and Health, 18, 287-98.

Piedmont, R. (2002, March). The spiritual complex as a paradigm for understanding spiritual transcendence. Presentation at the Annual Convention of the Eastern Psychological Association, Boston, MA.
Reidinger, M.S., Dracup, K.A., \& Brecht, M. (2002). Quality of life in women with heart failure, normative groups, and patients with other conditions. American Journal of Critical Care, 11(3), 211219.

Schultz, E.K. (2005). The meaning of spirituality for individuals with disabilities. Disability and Rehabilitation, 27(21), 1283-1295.

Tanyi, R.A. (2006). Spirituality and family. Journal of Advanced Nursing, 27(2), 213-230.

U.S. Department of Health and Human Services, National Institute of Health, National Heart, Lung and Blood Institute. (2007). Retrieved January 22, 2007, from www.nhlbi.nih.gov/health/ public/lung/other/COPD fact.htm

Weinert, C. (2005). Chronically ill reveal women's views of health care. Online Journal of Rural Nursing and Healthcare, 5(2).

Post-print standardized by MSL Academic Endeavors, the imprint of the Michael Schwartz Library at Cleveland State University, 2016 